\title{
Pengembangan Buku Cerita Rakyat Berbahasa Jawa untuk Siswa SD Kelas IV Berkultur Madura
}

\author{
Nuril Hidayatul Kodir*, Muh Arafik, Achmad Taufiq \\ Universitas Negeri Malang, Jl. Semarang No. 5 Malang, Jawa Timur, Indonesia \\ *Penulis korespondensi, Surel: kodirnuril@gmail.com
}

Paper received: 5-7-2021; revised: 23-7-2021; accepted: 30-7-2021

\begin{abstract}
The purpose of this research and development produce book Javanese folklore for student with Madura culture, the criteria is valid and practical according to (1) specialist subject matter, (2) spesialist product, (3) specialist learning and (4) small group product trials and (5) large group trials. The model used is an adaptation of Sugiyono,s research and development. Validation subject matter done with a lecturer literatur Indonesia, validation product design done with lecturer KSDP and lecturer TEP, validation specialist learning done with a IV grade teacher SD Negeri Kotalama 1 Malang. Small group product trials done with 12 students, and large group trials done with 25 IV grade students SD Negeri Kotalama 1 Malang. Overall average validation results are 94,55 percent, small group product trials result 99,16 percent and large group trials result 98,4 percent. Based on that research and development book Javanese folklore for students with Madura culture which is considered very valid and very practical.
\end{abstract}

Keywords: folklore; Javanese language; student with Madura culture

\begin{abstract}
Abstrak
Tujuan penelitian dan pengembangan ini adalah menghasilkan media buku cerita rakyat Madura berbahasa jawa yang valid dan praktis menurut (1) ahli materi, (2) ahli media, (3) ahli pembelajaran, (4) uji coba kelompok kecil, dan (5) uji coba kelompok besar. Model yang digunakan merupakan adaptasi dari model penelitian dan pengembangan sugiyono. Validasi materi dilakukan oleh 1 orang dosen sastra Indonesia, validasi media dilakukan oleh 1 orang dosen KSDP dan 1 orang dosen TEP, serta validasi pembelajaran dilakukan oleh guru kelas IV SD Negeri Kotalama 1 Malang. Uji coba kelompok kecil dilakukan pada 12 siswa dan uji coba kelompok besar dilakukan pada 25 siswa kelas IV SD Negeri Kotalama 1 Malang. Keseluruhan rata-rata hasil uji validasi dengan persentase sebesar 94,55 persen, hasil uji coba kelompok kecil dengan persentase 99,16 persen dan uji kelompok besar dengan persentase 98,4 persen. Berdasarkan hal tersebut, maka media buku cerita rakyat Madura berbahasa jawa yang dikembangkan termasuk kriteria sangat valid dan sangat praktis.
\end{abstract}

Kata kunci: buku cerita rakyat; bahasa Jawa; siswa berkultur Madura

\section{Pendahuluan}

Bahasa yang memiliki Jumlah penutur terbanyak di Indonesia ialah Bahasa Jawa. Menurut Arafik (2017) Bahasa jawa dijadikan sebagai sarana untuk berkomunikasi, saling belajar, saling berbagi pengalaman, untuk meningkatkan kemampuan intelektual dan apresiasi sastra, karena hal itu bahasa jawa dijadikan mata pelajaran muatan lokal. Pembelajaran muatan lokal Bahasa Jawa diharapkan membantu peserta didik yang mempelajari muatan lokal Bahasa Jawa dapat mengenal dirinya, lingkungannya, menerapkan dalam tata krama budayanya, menghargai potensi bangsa Indonesia, sehingga peserta didik mampu mengemukakan perasaan dan gagasan, dan berpartisipasi dalam masyarakat (Arafik \& Rumidjan, 2016). Peraturan menteri pendidikan dan kebudayaan nomor 79 tahun 2014 menyatakan bahwa bahasa merupakan salah satu muatan lokal yang diberikan kepada peserta didik sesuai dengan keunikan atau potensi yang terdapat pada daerah tersebut paling banyak dua jam per minggu. 
Bahasa Jawa dan Bahasa Madura ditetapkan sebagai mata pelajaran muatan lokal yang diterapkan di sekolah, sebagaimana diatur dalam Peraturan Gubernur Jawa Timur nomor 19 tahun 2014. Dengan adanya Peraturan Gubernur Jawa Timur nomor 19 tahun 2014 maka seluruh siswa SD akan mendapatkan muatan lokal Bahasa Jawa termasuk siswa dengan latar belakang kultur Madura yang tinggal di daerah dengan penerapan muatan lokal Bahasa Jawa.

Penyebaran masyarakat Madura menurut Wiyata (2013) yaitu lebih dari separuh masyarakat Madura merantau atau berdomisili di luar Madura yang tersebar di seluruh Indonesia. Sejalan dengan hal itu pendapat dari Asikin, dkk., (2016) yang menyatakan penyebaran masyarakat Madura termasuk di Kota Malang terkonsentrasi pada Kelurahan Kotalama. Masyarakat madura di Kelurahan Kotalama menyesuaikan diri dengan menggunakan Bahasa Jawa dengan dialek Malang, selain Bahasa Madura untuk berkomunikasi. Salah satu SD Negeri yang terdapat pada Kelurahan Kotalama yaitu SD Negeri Kotalama 1 Malang yang memiliki siswa dengan kesulitan belajar Bahasa Jawa karena latar belakang kultur siswa dimana 97\% dari 107 siswa kelas IV SD Negeri Kotalama 1 Malang memiliki latar belakang kultur Madura. Meskipun siswa yang bersekolah di SD Negeri Kotalama 1 Malang mayoritas memiliki latar belakang kultur Madura, sekolah tetap menerapkan muatan lokal Bahasa Jawa karena mengikuti kebijakan dari dinas pendidikan Kota Malang.

Berdasarkan hasil observasi yang dilakukan peneliti saat melaksanakan KPL di kelas IV SD Negeri Kotalama 1 Malang pada tanggal 3 September 2020, permasalahan yang dirasakan oleh siswa adalah tidak memahami materi yang diberikan oleh guru karena latar belakang keluarga dan lingkungan peserta didik yang berkultur Madura. Siswa cenderung tidak tertarik dengan pembelajaran Bahasa Jawa karena Bahasa Jawa yang terdapat pada buku paket pegangan siswa "Tantri Basa Kelas 4" menggunakan dialek Solo-Jogja dimana siswa berlatar belakang Madura tersebut telah terbiasa menyesuaikan diri menggunakan Bahasa Jawa dengan dialek Malang. Hasil wawancara dengan guru kelas IV SD Negeri Kotalama 1 Malang yang dilakukan pada tanggal 26 Januari tahun 2021, mengatakan bahwa siswa kelas IV SD Negeri Kotalama 1 Malang kurang tertarik mempelajari mata pelajaran Bahasa Jawa yang akhirnya membuat nilai siswa sering dibawah KKM. Siswa cenderung kurang tertarik dengan pembelajaran Bahasa Jawa karena tidak memahami bahasa dan materi yang dipelajari terutama pada materi cerita rakyat pada pada kompetensi dasar 3.1 dan kompetensi dasar 4.1 yang hanya berupa teks cerita panjang tanpa ilustrasi yang menarik. Materi yang dirasa sulit ialah pada materi cerita rakyat, karena harus membaca cerita yang panjang dengan dialek yang berbeda sehingga guru perlu menerjemahkan kedalam Bahasa Jawa dialek Malang.

Berdasarkan angket yang peneliti bagikan pada tanggal 15 Februari kepada 8 siswa kelas IV SD Negeri Kotalama 1 Malang. Hasil yang didapatkan dapat dipersentasekan sebagai berikut, $87,5 \%$ siswa berasal dari latar belakang kultur Madura, 100\% siswa merasa senang apabila belajar Bahasa Jawa menggunakan media pembelajaran, 87,5\% siswa merasa kesulitan mempelajari Bahasa Jawa materi cerita rakyat, 87,5\% siswa senang membaca cerita rakyat, dan $100 \%$ siswa tertarik membaca buku cerita rakyat yang berasal dari Madura. Semua siswa merasa senang mempelajari Bahasa Jawa menggunakan media pembelajaran, namun pemanfaatan media pembelajaran Bahasa Jawa belum pernah diterapkan oleh guru kelas IV SD Negeri Kotalama 1 Malang, padahal media pembelajaran dapat membantu dan memudahkan guru menyampaikan materi kepada peserta didik.Media pembelajaran dapat dipahami sebagai segala sesuatu yang dapat menyampaikan atau menyalurkan pesan dari sumber pesan kepada 
sasaran atau penerima pesan tersebut sehingga dapat membantu pencapaian keberhasilan dalam belajar (Mahnun, 2012).

Menurut Asyhar (2012) Proses pembelajaran merupakan proses komunikasi antara guru dan peserta didik, sebagai sebuah proses komunikasi di dalam prosesnya pastinya menghadapi hambatan-hambatan. Dari pernyataan tersebut dapat kita ketahui bahwa dalam proses pembelajaran, media pembelajaran memiliki peran untuk mengatasi hambatanhambatan yang terjadi dan mengharuskan guru untuk lebih kreatif dan inovatif dalam membuat serta memanfaatkan media pembelajaran yang berfungsi sebagai alat komunikasi antara guru dan peserta didik. Banyak media pembelajaran muatan Bahasa Jawa yang dapat menarik minat belajar peserta didik sekolah dasar, salah satunya adalah buku cerita rakyat yang memiliki warna dan ilustrasi menarik. Buku cerita rakyat dipilih, karena sesuai dengan hasil observasi, wawancara dan angket dimana belum tersedianya media untuk menunjang pembelajaran Bahasa Jawa terutama pada materi cerita rakyat. Cerita rakyat juga dapat dimanfaatkan guru untuk menanamkan etika dan moral kepada siswa. Melalui tokoh yang ada pada cerita rakyat siswa dapat meneladani etika dan moral tersebut (Kristanto, 2014).

\section{Metode}

Pengembangan buku cerita rakyat berbahasa Jawa menggunakan metode penelitian dan pengembangan (research and development). Metode penelitian dan pengembangan adalah metode yang digunakan untuk menghasilkan produk tertentu dan menguji keefektifan produk tersebut (Sugiyono, 2013). Model penelitian yang digunakan dalam penelitian ini mengadopsi penelitian dan pengembangan Sugiyono. Menurut Permana (2014) langkah-langkah pengembangan pada model Sugiyono sistematis dan mudah dilaksanakan dalam melakukan penelitian. Menurut Permana (2014) langkah-langkah pengembangan pada model Sugiyono sistematis dan mudah dilaksanakan dalam melakukan penelitian. Pelaksanaan penelitian pengembangan buku cerita rakyat Madura berbahasa Jawa hanya terbatas sampai tahapan ke sembilan dari model Sugiyono, yaitu revisi produk akhir. Hal tersebut dilakukan peneliti karena terbatasnya waktu dan biaya untuk melakukan produksi massal dengan mencetak buku cerita rakyat Madura berbahasa Jawa. Tahapan penelitian dan pengembangan secara urut yaitu: (1) potensi dan masalah, (2) pengumpulan data, (3) desain produk, (4) validasi desain, (5) revisi desain, (6) uji coba produk, (7) revisi produk, (8) uji coba pemakaian, (9) revisi produk akhir.

Uji coba produk bertujuan untuk mengetahui kelayakan produk yang dikembangkan. Tahap uji coba produk yang dilaksanakan pada penelitian dan pengembangan ini adalah tahap konsultasi kepada dosen pembimbing, tahap validasi ahli materi, ahli media dan ahli pembelajaran, serta tahap uji lapangan yaitu uji coba kelompok kecil dan besar. Subjek uji coba dalam penelitian dan pengembangan ini meliputi ahli materi, ahli media, ahli pembelajaran dan siswa. Ahli materi materi dilakukan oleh 1 orang dosen sastra Indonesia, validasi media dilakukan oleh 1 orang dosen KSDP dan 1 orang dosen TEP, serta validasi pembelajaran dilakukan oleh guru kelas IV SD Negeri Kotalama 1 Malang. Uji coba kelompok kecil dilakukan pada 12 siswa dan uji coba kelompok besar dilakukan pada 25 siswa kelas IV SD Negeri Kotalama 1 Malang.

Hasil wawancara arahan, saran dan masukan dari ahli materi, media, pembelajaran, dan siswa dianalisis dengan kualitatif. Miles and Huberman (1984) dalam Sugiyono (2013:337) mengemukakan bahwa aktivitas dalam analisis data yaitu pengumpulan data, reduksi data, 
penyajian data dan simpulan. Data kuantitatif berupa angket validasi untuk para ahli dan angket kepraktisan untuk siswa, data kuantitatif yang diperoleh dari pengumpulan angket menggunakan skala likert untuk para ahli dan menggunakan skala guttman untuk siswa. Menurut Sugiyono (2013) jawaban pada item instrumen menggunakan skala likert mempunyai gradasi dari sangat positif sampai sangat negatif. Data kuantitatif berupa angket diolah dengan cara dibuat persentase dengan rumus analisis (Akbar, 2017) sebagai berikut.

$V a h=\frac{T S e}{T S h} \times 100 \%$

\section{Keterangan:}

Vah :Validasi ahli

TSe :Total skor empirik yang dicapai

TSh :Total skor yang diharapkan

Tabel 1. Kriteria Kategorisasi Hasil Validasi

\begin{tabular}{ccl}
\hline No. & Tingkat Pencapaian (\%) & \multicolumn{1}{c}{ Keputusan Uji } \\
\hline 1. & $85,01 \%-100,00 \%$ & $\begin{array}{l}\text { Sangat valid, sangat efektif, dapat digunakan tanpa } \\
\text { perbaikan. }\end{array}$ \\
2. & $70,01 \%-85,00 \%$ & $\begin{array}{l}\text { Cukup valid, cukup efektif, dapat digunakan namun perlu } \\
\text { perbaikan kecil. } \\
\text { Kurang valid, kurang efektif, perlu perbaikan besar, } \\
\text { disarankan tidak dipergunakan. }\end{array}$ \\
3. & $50,01 \%-70,00 \%$ & $\begin{array}{l}\text { Tidak valid, tidak efektif, tidak bisa digunakan. } \\
\text { Sangat tidak valid, sangat tidak efektif, tidak bisa digunakan. }\end{array}$ \\
5. & $01,00 \%-50,00 \%$ &
\end{tabular}

Sumber: Akbar (2017)

Angket yang diberikan pada siswa bertujuan untuk mengetahui tingkat kepraktisan media buku cerita rakyat berbahasa Jawa, ketika dilakukan uji coba ke-1 dan ke-2. Data yang diperoleh dari angket tersebut dianalisis menggunakan skala guttman. Apabila siswa "setuju" maka diperoleh nilai 1 dan nilai 0 jika "tidak setuju". Selanjutnya angket dapat dianalisis menggunakan rumus Arikunto (1999).

$P=\frac{\sum x}{N} x 100 \%$

\section{Keterangan:}

$\mathrm{P} \quad$ :Persentase skor

$\sum \mathrm{x} \quad$ :Jumlah skor

$\mathrm{N} \quad$ :Jumlah skor maksimal

Tabel 2. Kriteria Kategorisasi Kepraktisan

\begin{tabular}{ccl}
\hline Tingkat Pencapaian (\%) & Kategori & \multicolumn{1}{c}{ Keputusan Uji } \\
\hline $76 \leq \mathrm{P} \leq 100$ & Sangat Praktis & Dapat digunakan tanpa revisi \\
$51 \leq \mathrm{P} \leq 75$ & Praktis & Dapat digunakan, namun perlu revisi kecil \\
$26 \leq \mathrm{P} \leq 50$ & Kurang Praktis & Dapat digunakan dengan dengan revisi besar \\
$0 \leq \mathrm{P} \leq 25$ & Tidak Praktis & Tidak boleh digunakan \\
\hline
\end{tabular}

Sumber: Yamasari (2010) 


\section{Hasil dan Pembahasan}

Menurut Sunaengsih (2018) dalam pelaksanaan pembelajaran salah satu faktor penentu berhasil atau tidak berhasilnya proses pembelajaran adalah media pembelajaran. Media yang dihasilkan haruslah melalui seluruh proses uji validasi dan uji coba produk agar dapat membantu proses pembelajaran menjadi lebih baik. Produk yang dihasilkan berupa media buku cerita rakyat Madura berbahasa Jawa untuk siswa berkultur madura kelas IV SD Negeri Kotalama 1 Malang telah melalui seluruh proses uji validasi dan uji coba produk kelompok kecil dan kelompok besar. Berikut penyajian dan analisis data temuan dari tahap uji.

\subsection{Data Hasil Validasi Ahli Materi}

Media buku cerita rakyat berbahasa Jawa divalidasi oleh Teguh Tri Wahyudi, S.S., M.A. selaku validator ahli materi yang memiliki kualifikasi sebagai dosen jurusan sastra Indonesia Universitas Negeri Malang yang melaksanakan penilaian pada tanggal 17 Maret 2021. Berdasarkan uji validasi materi, diperoleh hasil persentase sebesar 96,25\%. Hasil persentase tersebut menyatakan bahwa media buku cerita rakyat berbahasa Jawa termasuk kategori sangat valid. Keputusan uji yang didapat untuk media buku cerita rakyat berbahasa Jawa ini adalah dapat digunakan tanpa perbaikan. Meskipun hasil persentase menyatakan bahwa media buku cerita rakyat berbahasa Jawa termasuk kategori sangat valid, namun menurut masukan dan saran ahli materi masih terdapat bagian yang perlu direvisi. Bagian yang perlu direvisi ialah masih terdapat Bahasa Jawa dengan dialek mataraman (Jogja-Solo) dan ukuran font ditambah menjadi 16. Faktor-faktor kesulitan siswa dalam mempelajari Bahasa Jawa yaitu, kosakata dalam bahasa Jawa yang dipelajari tidak sering didengar dalam kegiatan sehari-hari yang cenderung menggunakan Bahasa Jawa dialek Malang, sebab Bahasa Jawa yang digunakan dalam pembelajaran menggunakan dialek Solo-Yogya (Endryanti, dkk., 220).

\subsection{Data Hasil Validasi Ahli Media}

Media buku cerita rakyat berbahasa Jawa divalidasi oleh Dra. Hj. Sukamti., M.Pd selaku validator ahli media pertama yang memiliki kualifikasi sebagai dosen jurusan pendidikan guru sekolah dasar (PGSD) Universitas Negeri Malang yang melaksanakan penilaian pada tanggal 18 Maret 2021 .Selain itu media buku cerita rakyat berbahasa Jawa divalidasi juga divalidasi oleh Eka Pramono Adi, S.IP, M.Si selaku validator ahli media kedua yang memiliki kualifikasi sebagai dosen jurusan teknologi pendidikan (TEP) Universitas Negeri Malang yang melaksanakan penilaian pada tanggal 23 Maret tahun 2021. Berdasarkan hasil validasi ahli media I mendapatkan hasil persentase kelayakan sebesar $84,72 \%$. Hasil persentase tersebut menyatakan bahwa media buku cerita rakyat berbahasa Jawa termasuk kategori cukup valid, cukup efektif, dapat digunakan namun perlu perbaikan kecil. Berdasarkan masukan dan saran yang diberikan oleh ahli media I, perbaikan yang dilakukan ialah memperbaiki tulisan yang kurang jelas dan kontras warna pada sampul belakang, mengubah kata kamus menjadi kamus cilik pada petunjuk, memperbaiki kata kerjakna menjadi garapen, dan mengubah gambar yang awalnya dipetak menjadi tidak dipetak. Sedangkan hasil validasi ahli media II mendapatkan hasil persentase kelayakan sebesar 98,16 \%. Hasil persentase tersebut menyatakan bahwa media buku cerita rakyat berbahasa Jawa termasuk kategori sangat valid dan dapat digunakan tanpa perbaikan. Pelaksanaan pembelajaran Bahasa Jawa di sekolah dasar juga merupakan bentuk pelestarian bahasa jawa melalui jalur formal, diharapkan dengan bimbingan dari guru siswa lebih mudah untuk mempelajari Bahasa Jawa (Utari, 2012). 


\subsection{Data Hasil Validasi Ahli Pembelajaran}

Media buku cerita rakyat berbahasa Jawa divalidasi oleh Kunardjiono, S.Pd selaku validator ahli pembelajaran yang memiliki kualifikasi sebagai guru kelas IV SD Negeri Kotalama 1 Malang yang melakukan penilaian pada tanggal 24 Maret 2021. Berdasarkan hasil uji validasi ahli pembelajaran dengan persentase kelayakan sebesar 98,64\%. Hasil persentase tersebut menyatakan bahwa media buku cerita rakyat berbahasa Jawa termasuk kategori sangat valid dan dapat digunakan tanpa perbaikan. Meskipun hasil persentase menyatakan bahwa media buku cerita rakyat berbahasa Jawa termasuk kategori sangat valid, namun menurut masukan dan saran ahli pembelajaran masih terdapat bagian yang perlu direvisi. Bagian yang perlu direvisi ialah membuat soal bervariasi dan menyamakan bentuk soal pada setiap cerita.

\subsection{Data Hasil Uji Kelompok Kecil}

Uji coba kelompok kecil ini dilakukan pada tanggal 29 Maret dan 30 Maret tahun 2021 di SD Negeri Kotalama 1 Malang, uji coba kelompok kecil ini dilakukan pada pukul 08.00 WIB sampai 09.00 WIB. Siswa yang dijadikan sampel pada uji kelompok kecil ini berjumlah 12 siswa. Berdasarkan hasil uji coba kelompok kecil diperoleh nilai dengan persentase kepraktisan sebesar 99,16\%. Persentase 99,16\% termasuk kategori sangat praktis dan dapat digunakan tanpa perlu adanya revisi. Namun berdasarkan uji lapangan, siswa kesulitan saat membaca buku di depan kelas karena buku dijilid spiral dan untuk menghindari rusaknya sikusiku pada buku peneliti memperbaiki buku dengan mengganti menjadi jilid tumpuk.

\subsection{Data Hasil Uji Kelompok Besar}

Uji coba kelompok besar ini dilakukan pada tanggal 5 April dan 6 April tahun 2021 di SD Negeri Kotalama 1 Malang, uji coba kelompok besar ini dilakukan pada pukul 09.00 WIB sampai 10.00 WIB. Siswa yang dijadikan sampel pada uji kelompok besar ini berjumlah 25 siswa. Berdasarkan hasil uji coba kelompok besar diperoleh penilaian dengan persentase kepraktisan sebesar 98,4\%, hasil tersebut termasuk kategori sangat praktis dan dapat digunakan tanpa perlu adanya revisi.

\subsection{Rekapitulasi Hasil Validasi dan Uji Coba Produk}

Produk berupa media buku cerita rakyat Madura berbahasa Jawa untuk siswa berkultur madura kelas IV SD Negeri Kotalama 1 Malang telah melalui seluruh proses uji validasi dan uji coba produk kelompok kecil dan kelompok besar. Hasil validasi dan uji coba produk siswa terhadap media buku cerita rakyat Madura berbahasa Jawa yang telah dilaksanakan secara keseluruhan adalah sebagai berikut.

Tabel 3. Hasil Validasi terhadap Media Buku Cerita Rakyat Madura berbahasa Jawa

\begin{tabular}{|c|c|c|c|}
\hline No. & Validator & Persentase & Kriteria \\
\hline 1. & Ahli Materi & $96,25 \%$ & Sangat valid, sangat efektif, dapat digunakan tanpa perbaikan. \\
\hline 2. & Ahli Media 1 & $84,72 \%$ & $\begin{array}{l}\text { Cukup valid, cukup efektif, dapat digunakan namun perlu } \\
\text { perbaikan kecil. }\end{array}$ \\
\hline 3. & Ahli Media 2 & $98,61 \%$ & Sangat valid, sangat efektif, dapat digunakan tanpa perbaikan. \\
\hline 4. & $\begin{array}{l}\text { Ahli } \\
\text { Pembelajaran }\end{array}$ & $98,64 \%$ & Sangat valid, sangat efektif, dapat digunakan tanpa perbaikan. \\
\hline
\end{tabular}




\section{Tabel 4. Hasil Uji Coba Produk Siswa terhadap Media Buku Cerita Rakyat Madura Berbahasa Jawa}

\begin{tabular}{cccc}
\hline No. & Penilaian & Persentase & Kriteria \\
\hline 1. & Uji coba kelompok kecil & $99,16 \%$ & Sangat praktis \\
2. & Uji coba kelompok besar & $98,4 \%$ & Sangat praktis \\
\hline
\end{tabular}

\section{Simpulan}

Berdasarkan hasil penelitian dan pembahasan dapat disimpulkan bahwa penelitian dan pengembangan ini menghasilkan produk media buku cerita rakyat Madura berbahasa Jawa yang valid menurut ahli materi, media dan pembelajaran, serta praktis menurut siswa. Berdasarkan validasi ahli materi diketahui mendapatkan hasil validitas materi sebesar $96,25 \%$ yang termasuk kriteria sangat valid. Hasil validasi ahli media I mendapatkan hasil validitas sebesar 84,72 yang termasuk kriteria cukup valid, sedangkan hasil validasi ahli media 2 mendapatkan hasil validitas sebesar 98,61\% yang termasuk kriteria sangat valid. Berdasarkan validasi ahli pembelajaran mendapatkan hasil validitas sebesar 98,64\%. Menurut hasil angket yang diperoleh dari peserta didik kelas IV yang meliputi uji coba produk kelompok kecil dan uji coba kelompok besar mendapatkan hasil 99,16 \% dan 98,4\% yang termasuk kriteria sangat praktis.

\section{Daftar Rujukan}

Arafik, M. (2017). Pembelajaran Literasi Bahasa Daerah di Sekolah Dasar. Malang: Fakultas Ilmu Pendidikan Universitas Negeri Malang.

Arafik, M., \& Rumidjan, R. (2016). Profil Pembelajaran Unggah-Ungguh Bahasa Jawa Di Sekolah Dasar. Sekolah Dasar: Kajian Teori Dan Praktik Pendidikan, 25(1), 55-61. Sekolah Dasar: Kajian Teori Dan Praktik Pendidikan, 25(1), 55-61.

Arikunto, S. (1999). Dasar-dasar Evaluasi Pendidikan. Jakarta: PT Bumi Aksara.

Asikin, dkk. (2016). Konservasi Spasial Dan Psikologi Pada Permukiman Migran Madura Kelurahan KotalamaMalang. Simposium Nasional RAPI XV, 294-301.

Asyhar, R. (2012). Kreatif Mengembangkan Media Pembelajaran. Jakarta: Referensi Jakarta.

Endryanti, E. R., Roekhan, R., \& Wijayati, P. H. (2020). Ayo Sinau Basa Jawa: Bahan Digital Penunjang Pembelajaran Kosakata Bahasa Jawa Berbasis Multimedia. Jurnal Pendidikan: Teori, Penelitian, dan Pengembangan, 5(3), 307-313.

Kristanto, M. (2014). Pemanfaatan Cerita Rakyat Sebagai Penanaman Etika Untuk Membentuk Pendidikan Karakter Bangsa. Mimbar Sekolah Dasar, 1(1), 59-64.

Kurniawan, H. (2013). Menulis Kreatif Cerita Anak. Jakarta: Akademia.

Mahnun, N. (2012). Media pembelajaran (kajian terhadap langkah-langkah pemilihan media dan implementasinya dalam pembelajaran). An-Nida', 37(1), 27-34.

Peraturan Gubernur Jawa Timur Nomor 19 Tahun 2014 Tentang Mata Pelajaran Bahasa Daerah Sebagai Muatan Lokal Wajib Disekolah/Madrasah. (https://jdih.surabaya.go.id/pdfdoc/pergub_19.pdf), diakses 22 Januari 2021.

Peraturan Menteri Pendidikan Dan Kebudayaan Nomor 79 Tahun 2014 Tentang Pengaturan Tentang Muatan Lokal Kurikulum 2013.(online),

Permana, D. R. I. K. (2014). Pengembangan Media Kartu Bergambar Magnetik Pada Mata Pelajaran Bahasa Inggris Materi Pokok Penguasaan Kosakata Pada Kelas Ii SDN Mojosari. Jurnal Pendidikan, 1(1), 1-10.

Sugiyono. (2013). Metode Penelitian Pendidikan. Bandung: Alfabeta.

Sunaengsih, C. (2016). Pengaruh Media Pembelajaran Terhadap Mutu Pembelajaran Pada Sekolah Dasar Terakreditasi A. Mimbar Sekolah Dasar 3(2):183-90. 
Jurnal Pembelajaran, Bimbingan, dan Pengelolaan Pendidikan, 1(7), 2021, 544-551

Utari, N. R. D. (2012). Kemampuan Berbahasa Jawa pada Siswa Sekolah Dasar di SDN Tandes Kidul I/110 Surabaya. Skriptorium, 1(3), 83-85.

Yamasari, Y. (2010). Pengembangan Media Pembelajaran Matematika Berbasis ICT yang Berkualitas. Seminar Nasional Pascasarjana X-ITS FMIPA Unesa.

Wiyata, A. L. (2013). Mencari Madura. Jakarta: Bidik Phronesis Publishing. 